\title{
Infidelity-Revealing Snapchat Messages Arouse Different Levels of Jealousy Depending on Sex, Type of Message and Identity of the Opposite Sex Rival
}

\author{
Michael J. Dunn ${ }^{1} \cdot$ Kayleigh Ward ${ }^{1}$ \\ Published online: 13 August 2019 \\ (C) The Author(s) 2019
}

\begin{abstract}
Research highlighting sex-differentiated jealousy resulting from imagined scenarios has now been reaffirmed when the infidelityrevealing message is discovered on a social media platform. Participants in the current study were presented with both sexually and emotionally charged infidelity-revealing scenarios featuring a same-sex sibling, a friend and a stranger in the format of a 'Snapchat' message. Men indicated significantly higher jealousy to sexual as opposed to emotional messages with the reverse pattern evident in women. Sex differences were also evident in the extent of jealousy elicited by 'third-party' identity. Women were significantly more jealous when the imagined infidelity occurred between their sister compared to both a best friend and a stranger with males showing significantly lower jealousy directed towards their brother compared to a stranger. These findings are supportive not only of a parental investment (PI) interpretation of sex differences in jealousy but also an interpretation consistent with aspects of inclusive fitness theory.
\end{abstract}

Keywords Infidelity $\cdot$ Snapchat $\cdot$ Evolutionary psychology $\cdot$ Jealousy type $\cdot$ Sex differences $\cdot$ Genetic relatedness

\section{Introduction}

Evidence points to a long history of non-monogamous, extra-pair mating behaviour in our species (Baker and Bellis 1995; Buss and Schmitt 1993; Gallup et al. 2003; Kinsey et al. 1948; Symons 1979). Jealousy, often defined as distrust or resentfulness towards significant others due to suspected or known romantic contact with a rival or interloper, is inextricably linked with infidelity (Wurmser and Jarass 2011). Jealousy provokes intolerance towards unfaithfulness, and this emotion often ensues when individuals believe they are losing a romantic relationship to a rival, with the emotion-motivating behaviour functioning to mitigate this eventuality (Parrot and Smith 1993; Buss 2005). Moreover, with the inception of the Internet, the contemporary romantic relationship-cheat or mate-poacher can operate in an environment clearly conducive to all types of infidelity.

Michael J. Dunn

mdunn@cardiffmet.ac.uk

1 Department of Applied Psychology, Cardiff Metropolitan University, Western Avenue, Cardiff CF5 2YB, UK
Evolutionary psychologists past and present have focussed much attention on the inextricably related phenomena of infidelity and jealousy (Buss and Haselton 2005; Buunk et al. 2019; Robins et al. 2000). This perspective views jealousy as an inherited mechanism that has evolved in humans to make them both hypervigilant of the dangers posed by potential mate-poaching rivals and sensitive to cues revealing one's partner's sexual or romantic interest in others (Buss 2005; Redlick 2016; Rotenberg et al. 2001). Sex differences in jealousy have been the primary focus of evolutionary psychologists (Buss et al. 1992; Levy and Kelly 2010). The explanation for this difference is that the loss of sexual exclusivity would have been catastrophic for ancestral males due to the dangers of being cuckolded and thus parting with prodigious amounts of investment to non-genetically related offspring (thus selection favouring sensitivity to sexual infidelity). For females, loss of a reliable high-investing male (which is inevitable if a male partner becomes emotionally involved with another female) is equally catastrophic to the woman as it would result in the loss of critically needed offspring resources. Thus, the evolution of sensitivity to emotional infidelity as emotional involvement with other women inevitably meant a loss or redirection of resources (Buss 2005). Current research is 
indebted to Buss et al. (1992) who initially revealed this inclination towards sexual jealousy in men and emotional jealousy in women. Their research exposed participants to sexual and emotional infidelity-revealing scenarios whilst also measuring electrodermal activity (EDA). Female EDA readings were higher when exposed to emotional infidelity-revealing scenarios compared to sexual, whereas male EDA readings peaked for sexual infidelity scenarios. Subsequent research, employing a variety of research methodologies, have supported these findings reinforcing the central finding that females are more distressed by emotional infidelity and males more so by sexual infidelity (Bassett 2005; Buunk et al. 1996; DeSteno and Salovey 1996; Sagarin et al. 2003).

As is the case with traditional offline infidelity, online infidelity typically revolves around an intimate, clandestine relationship with an individual other than a mate conducted with the use of modern technology. It tends to include social media/ text communications, picture swapping and sexual excitement (e.g. shared cyber-cam masturbation, sharing sexual fantasies) (Fincham and Beach 2010). Thus, this form of infidelity occurs even in the absence of offline sexual contact (Henline et al. 2007). Online infidelity has received copious amounts of attention in recent years (Maheu and Subotnik 2001; Mileham 2007; Vossler 2016) and, unsurprisingly, both males and females look upon online infidelity as an act of betrayal (Whitty 2005). An intriguing study conducted by Muise et al. (2009) showed a significant association between time spent on Facebook and jealousy. More broadly speaking, studies have shown sex differences in response to internet infidelity equate to sex differences observed in offline infidelity scenarios. For example, a recent qualitative study showed males to be more jealous when a winking emoticon was present in a Facebook message, whilst females were more jealous with no emoticon, suggesting males responded more so to a sexual jealousy cue (Hudson et al. 2015). Another study using an eye-tracker concluded that females fixated more than males on text messages revealing emotional infidelity, whereas males fixated more on text messages revealing sexual infidelity (Dunn and McLean 2015). Dunn and Billett (2018) have shown that distress to infidelity-revealing Facebook messages also may depend on the communicative direction and origin of the message. Women were found to experience significantly more distress to 'received' ('incoming messages from the other women') than to 'sent' messages ('outgoing messages from their partner'). In addition to non-physical forms of infidelity, social media platforms such as Facebook and Snapchat appear to encourage and facilitate offline infidelity. Snapchat is a photo-sharing app that permits users to send photos or videos to one or more friends. Utz et al. (2015) found that it is used more often for flirting and finding new partners and has been shown to evoke higher levels of jealousy than even Facebook. Predictable sex differences in the motivation to use Snapchat may also exist. Moran et al. (2018) discovered that men were more predisposed than women to use the app for hook-ups as were more unrestricted individuals.

With very few exceptions (Kostic and Yadon 2014; Shackelford and Buss 1996), studies have neglected to factor in information pertaining to the identity of the 'third party' that imagined relationship betrayals transpire with especially those adopting an evolutionary approach. No studies have thus far explored the extent to which jealousy may be aroused upon the discovery of infidelity through an online media source as a result of the emotional closeness, friendship status or genetic relatedness of an imagined 'interloper'. The current study addressed this shortcoming. Participants were asked to imagine the jealousy they would experience not only in their response to the type of message discovered by accessing their partner's Snapchat account (i.e. message revealing either emotional or sexual infidelity), but also by exploring potential differential distress elicited by partner infidelity with each of three types of third-party interloper, a 'stranger', a 'best friend' or a 'same-sex sibling'. As presenting participants with multiple examples of interloper is methodologically cumbersome, it was decided to select exemplars from three broad categories. When individuals engage in infidelity, often the third party is unknown to the victim. Hence, 'stranger' was used to represent this scenario. Often however individuals begin extra-pair affairs with friends, work colleagues and acquaintances. One could argue that the discovery of infidelity with the victims 'best friend' would likely arouse a high degree of jealousy. Best friend was therefore used to represent this category of interloper. Finally, the degree of jealousy elicited by the discovery via social media of infidelity with the 'same-sex sibling' of the victim is highly intriguing, especially if one adopts an 'inclusive fitness' theoretical position (Hamilton 1964a, b). In this case, genetic relatedness could feasibly mitigate against the manifestation of jealousy, i.e. even though partner/samesex sibling infidelity is distressing, offspring resulting from this type of infidelity would possess a higher coefficient of relatedness ' $r$ ' to the victim than both a stranger and a best friend. Thus, in addition to predicting a similar interaction between sex and type of infidelity as documented in previous studies supporting evolutionary theory, it is also hypothesised that when imagining three scenarios depicting infidelity with a 'stranger', 'best friend' and 'same-sex sibling' that lower jealousy would be reported for the latter compared to the two former hypothetical scenarios.

\section{Method}

\section{Pilot Study}

A pilot study was conducted on 4 males and 4 females (friends and acquaintances of the researchers, although each was unaware of the others involvement in the study) in order to gauge 
message authenticity, particularly in terms of the responses they evoked. All participants in this pilot were frequent users of Snapchat. Compared to short messages (15 words), longer messages (40 words) were reported as being more jealousy evoking. Consequently, messages were lengthened to 40 words. Feedback also suggested that a concerted effort would be needed to disambiguate the emotional and sexual content of the constructed messages. Messages were edited to clarify as much as possible that no sexual contact had occurred in the emotional infidelity-revealing messages and that sexual contact devoid of any emotional attachment was evident in the sexual infidelity-revealing messages. Furthermore, the pilot study participants agreed that swear words and emojis are prevalent in typical Snapchat messages pertaining to sexting, and the more the better, so it was decided to include 4 swear/ curse words and 3 emojis in each message to enhance authenticity/ecological validity. Suggestive emojis were used for the sexual messages, and love-related emojis for the emotional messages, to further emphasise the distinction between the message types (see Fig. 1 a-d).

\section{Participants}

The sample comprised of an opportunity sample of male $(n=$ $32)$ and female $(n=44)$ undergraduate students $M_{\text {age }}=21.5$, $\mathrm{SD}=4.01$. Using PS software, it was estimated that in excess of 30 participants per sex was required in order to detect statistically significant sex differences. This was also deemed a suitable study population as 37\% of Snapchat users are aged 18-24 (Bayer et al. 2016). Self-identified heterosexuality was the only inclusion criterion.

\section{Design}

A mixed design was employed. There were three IVs. The only between-subjects IV was the sex of the participant (male or female) and the two within-subjects IVs were the message type (sexual or emotional) and identity of the third-party rival (same-sex sibling, same-sex best friend and same-sex stranger). Presentation of messages was counterbalanced. There was one DV. This was the participant's reported level of imagined jealousy for each scenario, and this was measured using a linear rating scale, where 0 was not at all jealous and 10 was very jealous.

\section{Materials}

Information sheets were utilised to inform participants about the study and to pre-warn them that offense may be caused due to the sexually explicit nature of the messages they would be exposed to. The messages were censored at the request of the overseeing ethics committee. Consent forms were signed by participants before commencement of the study. The wording of the 'discovered' Snapchat messages (presented on PowerPoint) revealed either that emotional or sexual infidelity had occurred with the sexual messages being clearly sex specific. Presentations were constructed to effectively provide information on who the infidelity messages were sent from (the three infidelity scenarios). The Snapchat app itself was used to produce these messages, thus facilitating their genuine appearance. Although participants were not formally asked if they used the app, current statistics show that $90 \%$ of all 13 24-year-olds are users and no participants indicated their nonfamiliarity (Zephoria digital marketing 2019). Each PowerPoint slide contained a content-matched sex-specific sexual message for each infidelity scenario and a contentmatched sex-specific emotional message for each infidelity scenario (see example Fig. 1 a-d).

\section{Procedure}

Testing took place in a sound-attenuated room. Participants were presented with the information sheet and consent form first, and left alone for $5 \mathrm{~min}$ to read both sheets and sign the consent form. They were then invited to ask the researcher any questions pertinent to the study before it commenced. Once this was completed, participants were given the answer sheets and asked to engage with the PowerPoint without any specified time constraints until study completion. The PowerPoint slides presented the Snapchat message images, and these depicted their partner's imagined infidelity. This was preceded by inviting participants to imagine looking at a current partner's phone and noticing a Snapchat notification revealing the documented occurrence of both emotional, and sexual, infidelity between a romantic partner and a same-sex sibling, a best friend and a stranger. Males and females were subjected to different messages because they were sex specific to the participant and the infidelity scenarios, hence the separate PowerPoint presentations. Thus, in total, the participants were exposed to six scenarios: (1) emotional message from samesex sibling, (2) emotional message from same-sex best friend, (3) emotional message from same-sex stranger, (4) sexual message from same-sex sibling, (5) sexual message from same-sex best friend, (6) sexual message from same-sex stranger. Participants were randomly allocated to complete either emotional scenarios before sexual or vice versa. The sequence in which the third-party identity was presented was also randomised. The study took no longer than 20 minutes to complete. Once the study was completed, the researcher expressed gratitude for the participant's involvement and contribution. Debriefing was provided if requested.

\section{Method of Analysis}

A three-way, mixed ANOVA $(2 \times 2 \times 3)$ was employed. Simple main effect analyses and post hoc tests were used to 
identify differences between conditions. IBM SPSS 23 statistical programme was used to run the analysis.

\section{Ethical Considerations}

The Cardiff Metropolitan University ethics panel gave this study ethical approval on 19 October 2016.

\section{Results}

Pilot study data was not included. The data set involved 76 heterosexual participants in total in the final analysis, 32 males and 44 females (see Fig. 2). A priori power analyses using GPower (Faul et al. 2007) revealed, using a repeated measures, within-between interaction with alpha at 0.05 and Power $(1-\beta)$ set at 0.80 that the sample size required to detect a medium (0.059) effect size showed where there would be an $80 \%$ chance of correctly rejecting the null hypothesis of no significant effect of an interaction between third-party identity $\times$ sex was 82 participants. Regarding sex $\times$ infidelity type, with the same parameters, it was calculated that there would be an $80 \%$ chance of correctly rejecting the null hypothesis with a total of 54 participants.

Data was subjected to a 3-way mixed ANOVA with a between-subject factor of sex and within-subject factors of message type (sexual infidelity revealing/emotional infidelity revealing), and identity of third-party interloper (SSS, BF or stranger). Analysis revealed no significant main effect of sex $F<1$, relatedness $F<1$ or message $F_{1,73}=3.62, p>0.05$, $\eta^{2}=0.05$. However, highly significant third-party identity $\times$ sex $F_{2,146}=9.36, p<0.01, \eta^{2}=0.11$ and message $\times$ sex $F_{1,146}=21.0, p<0.01, \eta^{2}=0.22$ interactions were reported. Neither third-party identity $\times$ message nor third-party identity $\times$ message $\times$ sex interactions reached statistical significance $F_{2,146}=2.73, p>0.05, \eta^{2}=0.03$, and $F_{2,146}=1.54 p>0.05$, $\eta^{2}=0.02$ respectively.

Subsequent simple main effect analyses found that women overall expressed more imagined jealousy in response to discovering infidelity between their partner and a same-sex sibling than men $F_{1,73}=6.81 p<0.01, \eta^{2}=0.08$; however, no differences were observed in jealousy between women and men for both partner infidelity with a best friend $F<1$, or with a stranger $F<1$. With regard to intra-sexual differences, differences were evident for both women $F_{2,72}=4.62 p<0.05$, $\eta^{2}=0.11$ and men $F_{2,72}=3.46 p<0.05, \eta^{2}=0.09$. Women expressed significantly higher jealousy overall when imagining infidelity between a partner and a sister than they did to both infidelity between their partner and a best friend $(p<0.01)$ and their partner and a stranger $(p<0.05)$. Conversely, men indicated significantly less jealousy overall imagining infidelity between their brother and their partner than between their partner and a stranger $(p<0.05)$. With
Fig. 1 a-d Showing sex-specific messages presented to participants. Figure panels $\mathbf{a}$ and $\mathbf{b}$ are messages presented to female participants (a $=$ emotional and $\mathbf{b}=$ sexual) and figure panels $\mathbf{c}$ and $\mathbf{d}$ are messages presented to male participants $(\mathrm{c}=$ emotional and $\mathrm{d}=$ sexual $)$

regard to differences between and within the sexes relating to message type, women participants irrespective of identity of rival evidenced statistically higher jealousy imagining their partner engaged in emotional as opposed to sexual infidelity $F_{1,73}=4.35 p<0.05, \eta^{2}=0.05$. This difference was reversed for men who clearly evidenced higher imagined jealousy to sexual as opposed to emotional infidelity overall $F_{1,73}=17.94$ $p<0.01, \eta^{2}=0.2$. Women showed higher jealousy than men in response to Snapchat messages revealing emotional infidelity conducted by their partner $F_{1,73}=8.02 p<0.01, \eta^{2}=0.10$; however, no differences were reported between the sexes overall in jealousy evoked by imagining sexual infidelity between their partner and a third party $F_{1,73}=1.01 p>0.05$, $\eta^{2}=0.006$.

\section{Discussion}

The central thrust of the current research was to (1) establish if sex differences existing in jealousy manifestation upon the discovery of infidelity-revealing social media (Snapchat) messages are reflective of those found in the offline world and (2) to explore the extent to which feelings of jealousy elicited by imagined infidelity discovered whilst snooping on a partner's Snapchat account differ depending on the identity of the third party. Broad support for the evolutionary psychological perspective was found as women reported more jealousy to emotional than sexual infidelity and higher emotional jealousy overall in comparison to males, whereas males reported higher jealousy to sexual as opposed to emotional partner infidelity. No differences were recorded however between men and women with regard to jealousy elicited by sexual infidelity. The identity of the 'other-person' was also shown to have a considerable bearing on reported jealousy and, once again, intriguing sex differences were evident. Women experienced significantly higher jealousy when the same-sex rival was a sibling than when the rival was either a best friend or a stranger. Conversely, men reported significantly lower imagined infidelity-elicited jealousy directed towards their own brother than imagined infidelity-elicited jealousy occurring between their partner and a same-sex stranger.

Firstly, the current study augments a growing body of research showing modest yet consistent sex differences in jealousy manifestation resulting from the discovery of infidelity online with women showing more pronounced emotional jealousy than sexual jealousy, and men more pronounced sexual jealousy than emotional jealousy (Dunn and Billett 2018; Dunn and McLean 2015; Groothof et al. 2009; Guadagno 


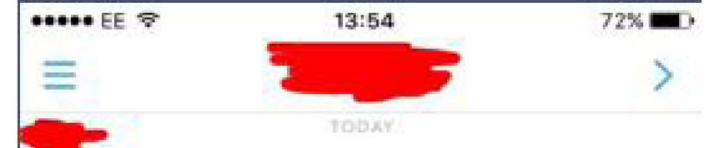

I f like half a person without you! if I've had a $s^{* \star \star}$ day, seeing your damn beautiful face changes everything $\$$ it doesn't matter that we haven't had sex, you're f******* worth waiting for $\vartheta \mathrm{x}$

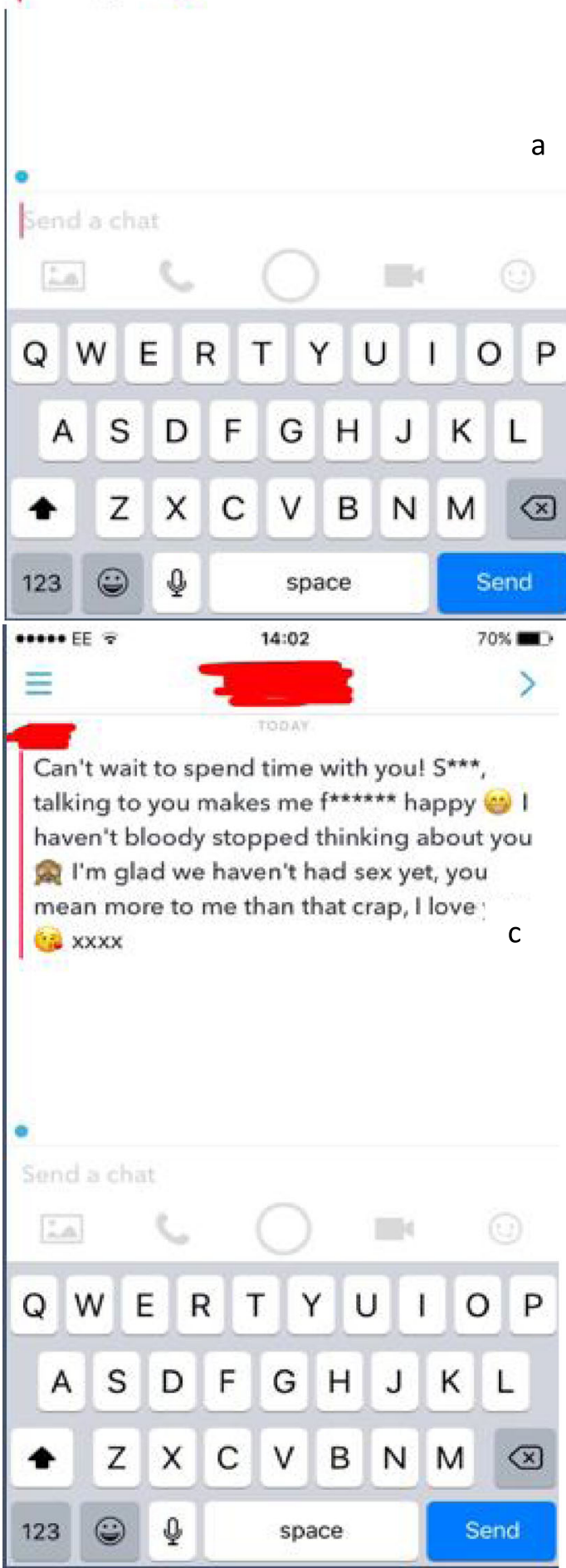

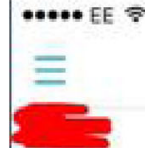

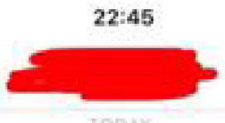

- $25 \%$

Loved jizzing all over your tits last night you filthy girl, I've never cummed so much in my life 0.9 best $f^{* * *}$ ever, next time I will have you screaming the place down! Send a dirty pic, you are so hot! 6 it $x$

6

Fend a chat

Q W E R T Y Y U I

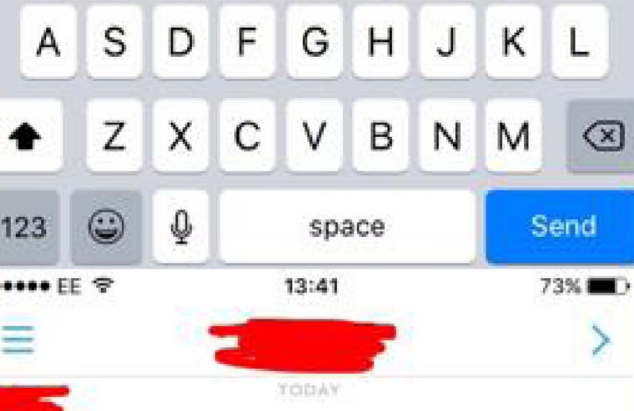

You have got the biggest dick I've ever had babe! I can't wait to ride you again, no other man has made me squirt before 0.0 ? looking forward to f $f^{\star \star \star \star \star \star}$ you again, next time I want you to f*t* me harderl $x \times x x$ d

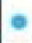

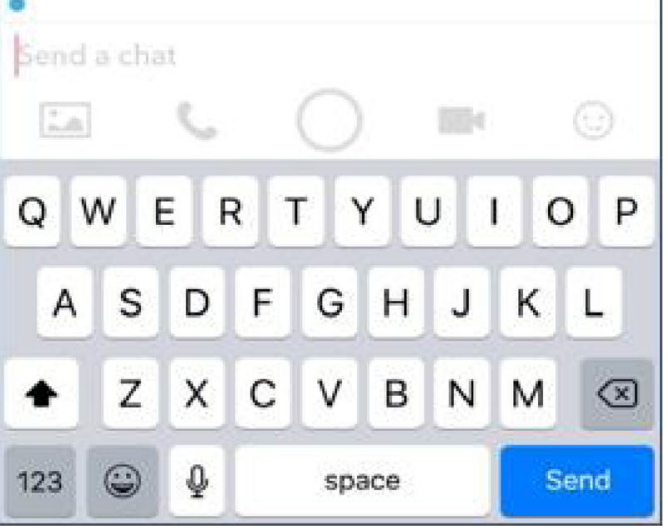


and Sagarin 2010; Hudson et al. 2015; Muise et al. 2014). These findings are supportive of sex differences consistently reported in offline jealousy-evoking scenarios (Archer 1996; Cann et al. 2001; Cramer et al. 2001; Fernandez et al. 2007; Harris 2002; Harris and Christenfeld 1996; Pietrzak et al. 2002; Schützwohl 2005; Schützwohl and Koch 2004). The findings also challenge the criticism that sex differences in jealousy are only evident using a forced-choice paradigm. Just as in the case of Bendixen et al. (2015), sex differences in the current study were found using continuous measures. In utilising Snapchat, this study has revealed that sex differences in jealousy manifestation in response to partner infidelity discovery are not restricted to text messages (Dunn and McLean 2015) or Facebook (Dunn and Billett 2018). One hypothesis, however, 'males will be significantly more jealous over the sexual messages than females', was not supported. A plausible explanation for this is that society may have become more sexualised over recent years (Gill 2012) and females have become more promiscuously inclined (Thornhill and Gangestad 2008) and more likely to engage in infidelity (Brand et al. 2007). Possibly, the enhanced opportunity to engage in online infidelity has resulted in both sexes becoming extra-vigilant of sexual betrayal. In a similar vein, Klettke et al. (2014) published a systematic literature review revealing no differences in the prevalence of sexting behaviour between men and women.

One unexpected finding relates to the fact that women were shown to be more jealous by the thought of infidelity occurring between their partner and their sister than between their partner and both their best friend or with a stranger. Biegler and Kennair (2016) found that when asked to list the relevance of traits either for their own or their sisters' idealised long-term partner even though they agreed on the majority of traits, differences were reported. Participants emphasised the importance of genetic fitness for their own idealised partners compared to what they thought would be good for their sister's idealised partner, e.g. that their sister's potential partners would prioritise extended family members. Consequently, there would be more direct rivalry between sisters for access to the best genetic mates during ovulation and these evolved mechanisms of heightened jealousy have filtered down to the modern technological world. In summary, the current study found that female relatives appear to possess more actual and genetic conflict than male relatives (Biegler and Kennair 2016) with sisters perhaps being more emotionally invested in each other than brothers (Fletcher et al. 2013).

One finding of particular prominence and significance in the current study is the fact that men were more tolerant of the distressing thought of infidelity revealed by a Snapchat message between their partner and their own brother than they were between their partner and a same-sex stranger. This is in direct contradiction of previous research findings showing that when invited to imagine partners having cheated, participants evidenced significantly higher distress when the partner infidelity was with a relative compared to a non-relative (Fisher et al. 2009). Kostic and Yadon (2014) have argued that

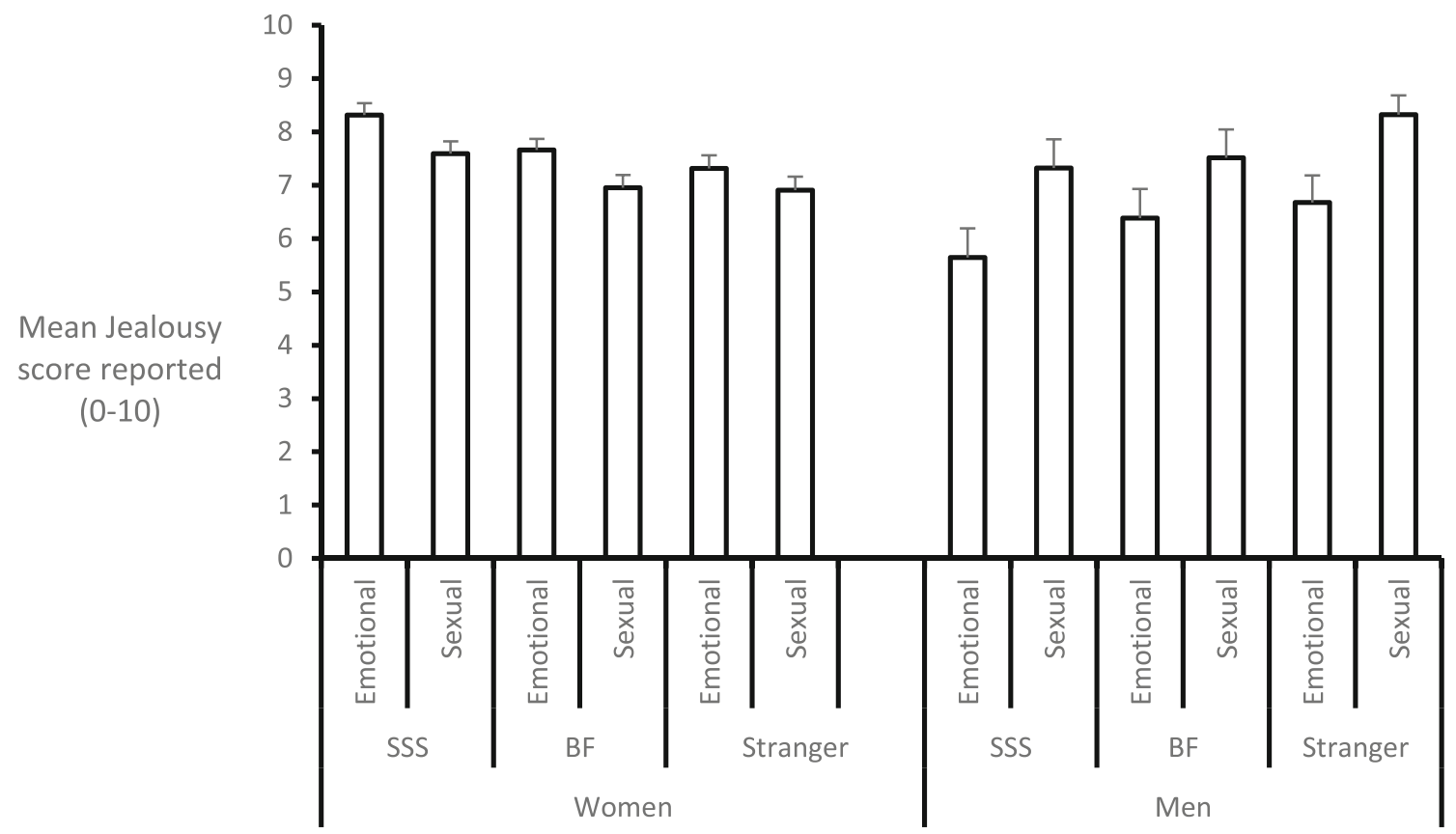

Fig. 2 Showing mean jealousy scores for men and women in response to either imagined emotional or sexual infidelity-revealing Snapchat messages sent from either a same-sex sibling (SSS), best friend (BF) or a stranger. Higher jealousy was recorded in females compared to males in response to emotional infidelity, whereas higher jealousy was recorded in

males compared to females in response to sexual infidelity. Jealousy was also higher when it was revealed that partner infidelity took place with a sister (SSS) compared to a best friend or stranger for females; however, lower jealousy was reported by males when the interloper was a brother (SSS) compared to a stranger. Values $=$ mean \pm SEM 
such higher distress may be explained by the fact that this is related to greater feelings of closeness with genetically related relatives. The current study differed in one prominent way from these earlier studies in that the jealousy-evoking scenarios were contextualised within a social media platform. The mitigation of jealousy by genetic relatedness in this case could be explained once again by adopting an evolutionary interpretation. Evolutionary psychology, like all scientific movements is guided by and owes enormous gratitude to the formulation and inception of key seminal theories. Hamilton's (1964a, b) inclusive fitness theory is one such theory. Not only did the theory solve the seemingly imponderable mystery of the existence of altruism in nature, it also allowed researchers to construct and test intricate hypotheses relating to a range of social behaviours. One key postulate is that individuals should show greater selfish restraint, and behave altruistically, when interacting with closer genetic relatives including those who are not directly related, e.g. sibling's offspring (Hamilton 1964a, b). In support of the theory, countless studies have shown that in a social context as genetic relatedness diminishes so does the degree of altruism directed from the donor to the recipient (Essock-Vitale and McGuire 1985; Burnstein et al. 1994; Korchmaros and Kenny 2008) with genetic relatedness being a strong predictor of subjective closeness (Stewart-Williams 2008). Apparent concerns for inclusive fitness costs pertaining to infidelity have been shown in a study where participants, regardless of their own sex, expressed most distress by a brother's partner's sexual infidelity and a sister's partner's emotional infidelity (Michalski et al. 2007). In summary, the current study illustrates that Hamilton's inclusive fitness theory is still relevant today in the technological era of 'Snapchat' at least with regard to explaining male jealousy attenuation to partner/sibling infidelity. After all, extra-pair copulation between a man's partner and a brother may still result nevertheless in genetically related offspring enhancing that man's inclusive fitness.

Before concluding, it is worthwhile pointing out potential weaknesses in the methodology of the study. Since the incorporation of scenario methods into research pertaining to infidelity and jealousy, and in an attempt to address challenges to the evolutionary position presented by authors such as DeSteno and Salovey (1996), researchers have repeatedly attempted to present sexual and emotional infidelity scenarios as being mutually exclusive (Buss et al. 1999). When constructing infidelity-revealing messages in a social media context, it is difficult for example to create an emotional infidelity scenario without at least hinting at the potential for future sexual liaison and vice versa. In addition to emphasising message 'ecological validity', future studies need to further disambiguate the two by for example making it clear that sexual infidelity is restricted to sexual cheating alone without any emotional involvement. For example, current research in our laboratory uses wording contained within a message such as 'we both know our affair will only ever be sexual' or 'nostrings attached' sexual fun.

In conclusion and in support of previous findings, it is argued that manifestly different jealousy inclinations in both sexes evolved as they were advantageous during the time of our EEA to help solve adaptive problems differentially pertinent to each sex (Geher and Miller 2012; Hart 2010). Moreover, the current study has provided evidence that sex differences in jealousy extend farther than purely inclinations towards jealousy type; there may also be sex differences in the extent to which third-party identity evokes jealousy. Miscellaneous adaptations pertaining to jealousy appear impervious to change in the current technological age. With a current pandemic in social media-mediated, jealousy-elicited infidelity, research utilising fictitious, jealousy-evoking scenarios may help shed light on, and hopefully mitigate, societal and personal problems associated with this phenomenon.

Compliance with Ethical Standards The Cardiff Metropolitan University ethics panel gave this study ethical approval on 19 October 2016.

Conflict of Interest The authors declare that they have no conflict of interest.

Open Access This article is distributed under the terms of the Creative Commons Attribution 4.0 International License (http:// creativecommons.org/licenses/by/4.0/), which permits unrestricted use, distribution, and reproduction in any medium, provided you give appropriate credit to the original author(s) and the source, provide a link to the Creative Commons license, and indicate if changes were made.

\section{References}

Archer, J. (1996). Sex differences in social behavior: Are the social role and evolutionary explanations compatible? American Psychologist, 51, 909-917.

Baker, R. R., \& Bellis, M. A. (1995). Human sperm competition: Copulation, masturbation, and infidelity. London: Chapman and Hall.

Bassett, J. F. (2005). Sex differences in jealousy in response to a partner's imagined sexual or emotional infidelity with a same or different race other. North American Journal of Psychology, 7, 71-84.

Bayer, J. B., Ellison, N. B., Schoenebeck, S. Y., \& Falk, E. B. (2016). Sharing the small moments: Ephemeral social interaction on Snapchat. Information, Communication \& Society, 19, 956-977.

Bendixen, M., Kennair, L. E. O., \& Buss, D. M. (2015). Jealousy: Evidence of strong sex differences using both forced choice and continuous measure paradigms. Personality and Individual Differences, 86, 212-216.

Biegler, R., \& Kennair, L. E. O. (2016). Sisterly love: Within-generation differences in ideal partner for sister and self. Evolutionary Behavioral Sciences, 10, 29-42.

Brand, R. J., Markey, C. M., Mills, A., \& Hodges, S. D. (2007). Sex differences in self-reported infidelity and its correlates. Sex Roles, 57, 101-109.

Burnstein, E., Crandall, C., \& Kitayama, S. (1994). Some neo-Darwinian decision rules for altruism: Weighing cues for inclusive fitness as a 
function of the biological importance of the decision. Journal of Personality and Social Psychology, 67, 773-789.

Buss, D. M. (2005). The dangerous passion: Why jealousy is as necessary as love and sex. New York: Odile Jacob.

Buss, D. M., \& Haselton, M. (2005). The evolution of jealousy. Trends in Cognitive Sciences, 9, 506-507.

Buss, D. M., \& Schmitt, D. P. (1993). Sexual strategies theory: an evolutionary perspective on human mating. Psychological Review, 100, 204-232.

Buss, D. M., Larsen, R. J., Westen, D., \& Semmelroth, J. (1992). Sex differences in jealousy: Evolution, physiology, and psychology. Psychological Science, 3, 251-255.

Buss, D. M., Shackelford, T. K., Kirkpatrick, L. A., Choe, J., Hasegawa, M., Hasagawa, T., \& Bennett, K. (1999). Jealousy and the nature of beliefs about infidelity: tests of competing hypotheses about sex differences in the United States, Korea, and Japan. Personal Relationships, 6, 125-150.

Buunk, B. P., Angleitner, A., Oubaid, V., \& Buss, D. M. (1996). Sex differences in jealousy in evolutionary and cultural perspective: tests from the Netherlands, Germany, and the United States. Psychological Science, 7, 359-363.

Buunk, A. P., Massar, K., Dijkstra, P., \& Fernandez, A. M. (2019). Intersexual and intrasexual competition and their relation to jealousy. In L. M. Welling \& T. K. Shackelford (Eds.), The Oxford Handbook of Evolutionary Psychology and Behavioral Endocrinology. Oxford Library of Psychology.

Cann, A., Mangum, J. L., \& Wells, M. (2001). Distress in response to relationship infidelity: the roles of gender and attitudes about relationships. Journal of Sex Research, 38, 185-190.

Cramer, R. E., Abraham, W. T., Johnson, L. M., \& Manning-Ryan, B. (2001). Gender differences in subjective distress to emotional and sexual infidelity: evolutionary or logical inference explanation? Current Psychology, 20, 327-336.

DeSteno, D. A., \& Salovey, P. (1996). Evolutionary origins of sex differences in jealousy? Questioning the 'Fitness' of the model. Psychological Science, 7, 367-372.

Dunn, M. J., \& Billett, G. (2018). Jealousy levels in response to infidelityrevealing Facebook messages depend on sex, type of message and message composer: support for the evolutionary psychological perspective. Evolutionary Psychological Science, 4(1), 17-23.

Dunn, M. J., \& McLean, H. (2015). Jealousy-induced sex differences in eye gaze directed at either emotional- or sexual infidelity-related mobile phone messages. Cyberpsychology, Behavior, and Social Networking, 18(1), 37-40.

Essock-Vitale, S. M., \& McGuire, M. T. (1985). Women's lives viewed from an evolutionary perspective: II. Patterns of helping. Ethology and Sociobiology, 6, 155-173.

Faul, F., Erdfelder, E., Lang, A.-G., \& Buchner, A. (2007). G*Power 3: a flexible statistical power analysis program for the social, behavioural, and biomedical sciences. Behavior Research Methods, 39, 175191

Fernandez, A. M., Vera-Villarroel, P., Sierra, J. C., \& Zubeidat, I. (2007). Distress in response to emotional and sexual infidelity: evidence of evolved gender differences in Spanish students. The Journal of Psychology, 141, 17-24.

Fincham, F. D., \& Beach, S. R. (2010). Marriage in the new millennium: a decade in review. Journal of Marriage and Family, 72, 630-649.

Fisher, M., Geher, G., Cox, A., Tran, U. S., Hoben, A., Arrabaca, A., \& Voracek, M. (2009). Impact of relational proximity on distress from infidelity. Evolutionary Psychology, 7, 560-580.

Fletcher, J., Mailick, M., Song, J., \& Wolfe, B. (2013). A sibling death in the family: common and consequential. Demography, 50, 803-826.

Gallup, G. G., Burch, R. L., Zappieri, M. L., Pawez, R. A., Stockwell, M. L., \& Davis, J. A. (2003). The human penis as a semen displacement device. Evolution and Human Behavior, 24, 277-289.
Geher, G., \& Miller, G. (2012). Mating intelligence: Sex, relationships, and the mind's reproductive system. London: Psychology Press.

Gill, R. (2012). The sexualisation of culture? Social and Personality Psychology Compass, 6, 483-498.

Groothof, H., Dijkstra, P., \& Barelds, D. (2009). Sex differences in jealousy: the case of Internet infidelity. Journal of Social and Personal Relationships, 26, 1119-1129.

Guadagno, R. E., \& Sagarin, B. J. (2010). Sex differences in jealousy: an evolutionary perspective on online infidelity. Journal of Applied Social Psychology, 40, 2636-2655.

Hamilton, W. D. (1964a). The genetical evolution of social behavior: I. Journal of Theoretical Biology, 7, 1-16.

Hamilton, W. D. (1964b). The genetical evolution of social behavior: II. Journal of Theoretical Biology, 7, 17-52.

Harris, C. R. (2002). Sexual and romantic jealousy in heterosexual and homosexual adults. Psychological Science, 13, 7-12.

Harris, C. R., \& Christenfeld, N. (1996). Gender, jealousy, and reason. Psychological Science, 7, 364-366.

Hart, S. L. (2010). Handbook of jealousy: Theory, research, and multidisciplinary approaches. Chichester: Wiley-Blackwell.

Henline, B. H., Lamke, L. K., \& Howard, M. D. (2007). Exploring perceptions of online infidelity. Personal Relationships, 14, 113-128.

Hudson, M. B., Nicolas, S. C., Howser, M. E., Lipsett, K. E., Robinson, I. W., Pope, L. J., Hobby, A. F., \& Friedman, D. R. (2015). Examining how gender and emoticons influence Facebook jealousy. Cyberpsychology, Behavior and Social Networking, 18, 87-92.

Kinsey, A. C., Pomeroy, W., \& Martin, C. (1948). Sexual behaviour in the human male. Philadelphia: WB Saunders.

Klettke, B., Hallford, D. J., \& Mellor, D. J. (2014). Sexting prevalence and correlates: a systematic literature review. Clinical Psychology Review, 34, 44-53.

Korchmaros, J. D., \& Kenny, D. A. (2008). Emotional closeness as a mediator of the effect of genetic relatedness on altruism. Psychological Science, 12, 262-265.

Kostic, B., \& Yadon, C. A. (2014). Infidelity and kin selection: does cheating seem as bad when it's "All in the family". Evolutionary Psychology, 12, 687-705.

Levy, K. N., \& Kelly, K. M. (2010). Sex differences in jealousy: a contribution from attachment theory. Psychological Science, 21, 168173.

Maheu, M. M., \& Subotnik, R. B. (2001). Infidelity on the Internet: Virtual relationships and real betrayals. Naperville: Source books.

Michalski, R. L., Shackelford, T. K., \& Salmon, C. A. (2007). Upset in response to a sibling's partner's infidelities. Human Nature, 18, 74 84.

Mileham, B. L. A. (2007). Online infidelity in Internet chat rooms: an ethnographic exploration. Computers in Human Behavior, 23, 1131.

Moran, J. B., Salerno, K. J., \& Wade, T. J. (2018). Snapchat as a new tool for sexual access: are there sex differences. Personality and Individual Differences, 129, 12-16.

Muise, A. M. Y., Christofides, E., \& Desmarais, S. (2009). More information than you ever wanted: does Facebook bring out the greeneyed monster of jealousy? Cyberpsychology \& Behavior, 12, 441444.

Muise, A. M. Y., Christofides, E., \& Desmarais, S. (2014). “Creeping” or just information seeking? Gender differences in partner monitoring in response to jealousy on Facebook. Personal Relationships, 21, $35-50$.

Parrot, W. G., \& Smith, R. H. (1993). Distinguishing the experiences of envy and jealousy. Journal of Personality and Social Psychology, 64, 906-920.

Pietrzak, R. H., Laird, J. D., Stevens, D. A., \& Thompson, N. S. (2002). Sex differences in human jealousy: A coordinated study of forcedchoice, continuous rating-scale, and physiological responses on the same subjects. Evolution and Human Behaviour, 23, 83-94. 
Redlick, M. (2016). The green-eyed monster: Mate value, relational uncertainty, and jealousy in romantic relationships. Personal Relationships, 23, 505-516.

Robins, R. W., Caspi, A., \& Moffitt, T. E. (2000). Two personalities, one relationship: both partners' personality traits shape the quality of their relationship. Journal of Personality and Social Psychology, 79, 251-259.

Rotenberg, K. J., Shewchuk, V. A., \& Kimberley, T. (2001). Loneliness, sex, romantic jealousy, and powerlessness. Journal of Social and Personal Relationships, 18(1), 55-79.

Sagarin, B. J., Becker, D. V., Guadagno, R. E., Nicastle, L. D., \& Millevoi, A. (2003). Sex differences (and similarities) in jealousy: the moderating influence of infidelity experience and sexual orientation of the infidelity. Evolution and Human Behavior, 24, 17-23.

Schützwohl, A. (2005). Sex differences in jealousy: the processing of cues to infidelity. Evolution and Human Behavior, 26, 288-299.

Schützwohl, A., \& Koch, S. (2004). Sex differences in jealousy: the recall of cues to sexual and emotional infidelity in personally more and less threatening context conditions. Evolution and Human Behavior, $25,249-257$.

Shackelford, T. K., \& Buss, D. M. (1996). Betrayal in mateships, friendships, and coalitions. Personality and Social Psychology Bulletin, 22(1), 1151-1164.
Stewart-Williams, S. (2008). Human beings as evolved nepotists: exceptions to the rule and effects of the cost of help. Human Nature, 19, 414-425.

Symons, D. (1979). The evolution of human sexuality. Oxford: New York.

Thornhill, R., \& Gangestad, S. W. (2008). The evolutionary biology of human female sexuality. Oxford: Oxford University Press.

Utz, S., Muscanell, N., \& Khalid, C. (2015). Snapchat elicits more jealousy than Facebook: a comparison of Snapchat and Facebook use. Cyberpsychology, Behavior and Social Networking, 18, 141-146.

Vossler, A. (2016). Internet infidelity 10 years on: a critical review of the literature. The Family Journal, 24, 359-366.

Whitty, M. T. (2005). The realness of cybercheating: men's and women's representations of unfaithful Internet relationships. Social Science Computer Review, 23, 57-67.

Wurmser, L., \& Jarass, H. (2011). Jealousy and envy: New views about two powerful feelings. Oxford: Taylor \& Francis https://zephoria. com/top-10-valuable-snapchat-statistics/.

Zephoria Digital Marketing. (2019). https://zephoria.com.

Publisher's Note Springer Nature remains neutral with regard to jurisdictional claims in published maps and institutional affiliations. 